\title{
Lectin Identification of Olfactory Receptor Neuron Subclasses with Segregated Central Projections
}

\author{
David R. Riddle, Lianna D. Wong, ${ }^{a}$ and Bruce Oakley \\ Neuroscience Program and Department of Biology, University of Michigan, Ann Arbor, Michigan 48109
}

\begin{abstract}
Our previous studies have demonstrated that the primary olfactory projection in rainbow trout is organized nontopographically; the pattern of termination of olfactory axons in the olfactory bulb is unrelated to the distribution of their cell bodies in the olfactory mucosa. In the present research we have further characterized the organization of this projection by examining the lectin-binding properties of olfactory receptor neurons. The results indicate that in trout, as in mammals, populations of olfactory receptor neurons differ significantly from one another in their carbohydrate "signatures." We have identified subsets of olfactory receptor neurons, specified by unique lectin-binding properties, that are widely distributed and intermingled with the other receptor neurons in the olfactory mucosa and nerve, but that segregate as they enter the olfactory bulb and project to restricted regions of the glomerular layer. This pattern of terminations is bilaterally symmetrical, is remarkably consistent across individuals, and reappears when the primary olfactory projection is reconstituted following transection of the olfactory nerve. As revealed by the carbohydrates on subpopulations of receptor neurons, there is substantial order in the nontopographic projection of olfactory receptor neurons to the offactory bulb. The functional significance of this organization and the means by which it develops and is maintained remain under investigation.
\end{abstract}

[Key words: olfactory bulb, odor, sensory coding, topography, axonal projections, teleosts]

A fundamental objective in the study of any sensory system is to elucidate the organization and connections of the neural regions subserving that sensory modality. In the most extensively studied sensory systems, point-to-point topographic projections create maps of the sensory space (in the visual and somatosensory systems) or maps of some dimension of the stimulus energy (tonotopic mapping in the auditory system). Compared to these sensory modalities the organization of the olfactory system remains poorly understood, but it does not appear that the organization is strictly topographic. Morphological studies of amphibians and mammals have indicated (1) that each olfactory receptor axon makes a single discrete termination in the olfac-

\footnotetext{
Received Sept. I1, 1992; revised Jan. 27, 1993; accepted Jan. 28, 1993.

This work was supported in part by a Rackham predoctoral fellowship to D.R.R. We thank $L$. H. Wu for technical assistance and D. Bay for photographic assistance. Correspondence should be addressed to David R. Riddle, Department of Neurobiology, Duke University Medical Center, Box 3209, Durham, NC 27710.

- Present address: Department of Molecular and Cell Biology, University of California, Berkeley, CA 94720.

Copyright (c) 1993 Society for Neuroscience $0270-6474 / 93 / 133018-16 \$ 05.00 / 0$
}

tory bulb, (2) that axons arising from neighboring olfactory receptor neurons may diverge in the olfactory bulb, and (3) that a given site in the bulb receives axons that converge from receptors from multiple sites in the olfactory epithelium. The organization of the primary olfactory system in mammals and amphibians is not random; the divergence and convergence of olfactory receptor axons has led to the characterization of the projections as regionally topographic rather than point to point (discussed in Kauer, 1981, 1987; Kauer et al., 1991; Shepherd, 1991; see also Discussion). A recent investigation suggests that olfactory projections in the rainbow trout may be organized by completely nontopographic rules (Riddle and Oakley, 1991). Small epithelial regions make divergent projections throughout the glomerular layer of the trout olfactory bulb, while any given point in the bulb is innervated by receptor neurons scattered throughout the entire olfactory epithelium. In trout, the divergence and convergence of primary olfactory axons is too extensive for the organization to be characterized as even regionally topographic.

Even in species in which the primary olfactory projection is regionally topographic, it is not evident how such organization would be useful to map the odor space or to localize the environmental source of an odorant. Odorants that emanate from a release site form turbulent, time-variant molecular streams in space. The entry of odor streams into the nasal passages creates further turbulence and molecular scattering. Consequently, it is difficult to imagine how a changing spatial distribution of odorant molecules adhering to the olfactory epithelium could encode the location of the environmental release site. Further, odor gradients are often flat relative to the small dimensions of the receptor organ. Unlike spatial localization in vision and touch, the localization of odorants appears to require more than a single stimulus sample; comparisons among successive samples are necessary (Kleerkoper, 1982; Døving, 1990).

It seems likely that neural maps in olfactory systems are based upon odor quality and other functional considerations rather than spatial localization (see Kauer, 1987; Kauer et al., 1991; Shepherd, 1991). Electrophysiological recording in amphibians and mammals provides support for the view that individual odorants preferentially excite subregions of the olfactory epithelium (Mustaparta, 1971; Thommeson and Døving, 1977; Mackay-Sim et al., 1982; Edwards et al., 1988) and olfactory bulb (Mustaparta, 1971; Thommesen, 1976, 1978; Døving et al., 1980; Kauer et al., 1987; Mori et al., 1990). Similarly, maps of metabolic activity in the olfactory bulb suggest that a given odorant increases activity in a subset of glomeruli (Sharp et al., 1973; Skeen, 1977; Stewart et al., 1979; Jourdan et al., 1980; Jourdan, 1982; Royet et al., 1987). The search for functionally 
based projection patterns has been enlivened by recent success in cloning genes for a family of putative olfactory receptor proteins (Buck and Axel, 1991). Subpopulations of sensory neurons expressing a subset of putative olfactory receptor proteins may be distributed uniformly throughout the olfactory epithelium (Cunningham et al., 1992), or may have more restricted distributions (L. Buck, personal communication).

The mapping of primary olfactory projections may be approached by using antibodies or lectins to identify subsets of olfactory receptor neurons. Several such markers have been used to demonstrate subsets of olfactory receptor cell axons that arise from a subregion of the epithelium and terminate in a subregion of the olfactory bulb (Allen and Akeson, 1985a,b; Fujita et al., 1985; Hempstead and Morgan, 1985a,b; Mori et al., 1985; Key and Giorgi, 1986a,b; Schwob and Gottlieb, 1986; Akeson, 1988; Morgan, 1988; Barber, 1989). The labeling pattern with some antibodies indicates that receptor cells widely scattered in the epithelium can converge to a subregion of the olfactory bulb (Mori, 1987; Shinoda et al., 1989; Mori et al., 1990). These antibody studies, and the activity mapping experiments cited above, are consistent with the hypothesis that functional subsets of olfactory receptor cells, which may be scattered peripherally, make convergent projections to the olfactory bulb.

In the present research we sought evidence for orderly convergent olfactory projections in a vertebrate that lacks a topographic primary olfactory projection. Lectin binding revealed subsets of olfactory receptor neurons that were intermingled and widely scattered in the olfactory epithelium and nerve, yet had highly segregated projections to restricted regions of the olfactory bulb. This suggests that the pattern of projections in the primary olfactory system in rainbow trout is not related to the spatial relationship between the epithelium and the olfactory bulb, but rather to demonstrable biochemical differences in the receptor neurons.

\section{Materials and Methods}

Rainbow trout (Oncorhynchus mykiss), 14-30 cm long, were obtained from Spring Valley Trout Farm (Dexter, MI) and maintained in 75 gallon aquaria at $14-16^{\circ} \mathrm{C}$. Ten normal trout were anesthetized by immersion in tricaine methane sulfonate (MS-222; $100 \mathrm{mg} /$ liter aquarium water) and perfused with heparinized physiological saline solution followed by fixative $\left(6 \% \mathrm{HgCl}_{2}, 1 \%\right.$ sodium acetate, $0.1 \%$ glutaraldehyde). Additional trout were anesthetized and decapitated; the olfactory system and brain were removed and fixed by immersion in the same fixative. Other fixatives tested included phosphate-buffered $4 \%$ paraformaldehyde, $2.5 \%$ paraformaldehyde $/ 0.2 \%$ glutaraldehyde, and $70 \%$ ethanol $/$ $10 \%$ acetic acid. The tissue was embedded in paraffin according to standard histological procedures and 6-10 $\mu \mathrm{m}$ sections were cut and mounted on gelatin-subbed slides. Parallel series of alternate sections from the olfactory rosette, nerves, and bulbs were prepared so that adjacent or nearly adjacent sections could be stained with different reagents (see below).

In addition to the normal tissue, sections of the olfactory mucosa, nerve, and bulb from trout in which the olfactory system had been lesioned (see Riddle and Oakley, 1992) were also investigated with lectins. In most of these animals the primary olfactory system was lesioned unilaterally by extirpating the olfactory mucosa, transecting the olfactory nerve, or resecting the olfactory bulb. In six trout the olfactory bulbs were removed bilaterally; in two of the six glass plates were placed anterior to the telencephalon to block regeneration of olfactory receptor neurons into the brain. The trout were allowed to survive for 2-14 weeks after surgery, after which they were anesthetized and perfused as described above.

Lectin labeling. A panel of eight biotinylated lectins (Table 1) was tested on sections of the olfactory rosette, olfactory nerve, and forebrain. The binding of pokeweed agglutinin (PWA) was investigated most extensively. All lectins were obtained from Sigma Chemical Co.
Table 1. The eight lectins tested in the present study are listed with their reported carbohydrate specificities (Sharon and Lis, 1989) and the concentrations at which they were used

\begin{tabular}{lll} 
Sugar specificity & Lectin(s) & Concentration (\%) \\
\hline Mannose & ConA & 0.001 \\
Galactose & PNA & 0.002 \\
$N$-acetylgalactosamine & SBA & $0.001-0.01$ \\
& DBA & $0.001-0.01$ \\
$N$-acetylglucosamine & PWA & $0.0001-0.01$ \\
& WGA & 0.001 \\
L-Fucose & UEA I & $0.001-0.01$ \\
$N$-acetylneuraminic acid & WGA & 0.001 \\
Oligosaccharides & PHA & 0.001 \\
\hline
\end{tabular}

Tissue fixed with $\mathrm{HgCl}_{2}$ was hydrated and treated with alcoholic iodine followed by $5 \%$ sodium thiosulfate to remove residual mercury. All sections were incubated in $0.3 \% \mathrm{H}_{2} \mathrm{O}_{2}$ to block endogenous peroxidase reactivity, exposed to the lectin $(0.0001-0.01 \%$ in phosphatebuffered saline) for $60 \mathrm{~min}$ at room temperature, and then incubated in avidin-biotin-peroxidase complex ( $\mathrm{ABC}$, Vector Labs) followed by $0.5 \%$ diaminobenzidine (DAB) with $0.3 \% \mathrm{H}_{2} \mathrm{O}_{2}$. All incubations were separated by several rinses in phosphate buffer. For double staining with polyclonal antisera (see below), lectin binding was sometimes visualized with streptavidin-Texas red (Bethesda Research Laboratories) rather than with $A B C$ and DAB. The carbohydrate specificities of the lectins were confirmed with appropriate sugars, including $N$-acetylglucosamine, $\mathrm{N}$-acetylgalactosamine, galactose, methyl-D-mannopyranoside, L-fucose, and the trisaccharide of acetylglucosamine, triacetylchitotriose (Sigma). In controls, lectins were preincubated with sugars of appropriate or inappropriate specificity (at $0.1 \mathrm{M}$, unless otherwise indicated) for $10 \mathrm{~min}$ at room temperature prior to exposure to the tissue. Other controls included replacing the lectin or $\mathrm{ABC}$ with buffer.

Immunocytochemistry. Since the first goal of the study was to identify subclasses of olfactory receptor neurons, it was useful to have a general marker of these cells with which to compare the patterns of lectin labeling. For this purpose we used antisera to keyhole limpet hemocyanin (anti-KLH; U.S. Biochemicals) to label adjacent sections or to doublc label sections reacted with lectins. Anti-KLH reacts with all or nearly all of the olfactory receptor neurons in trout (Riddle and Oakley, 1992). The antisera were used at a final dilution of 1:5000 in normal goat serum; antibody binding was detected with biotinylated goat anti-rabbit $\mathrm{IgG}$ (Sigma) and ABC or with an FITC-conjugated secondary antibody (Jackson Immunochemical).

For five fish, camera lucida drawings of every fourth section of one olfactory bulb were prepared from alternate sections labeled with PWA and anti-KLH. Using a digitizing tablet and microcomputer, the total area of the olfactory nerve layer and glomerular layer was measured in each section labeled with anti-KLH. The areas of the highly PWAreactive and moderately PWA-reactive regions (see Results) were measured in the adjacent sections. For each olfactory bulb the percentages of the olfactory nerve layer and glomerular laycr that were strongly PWA positive, moderately PWA positive, and PWA negative were determined (Table 2).

\section{Results}

The gross anatomy of the primary olfactory system in trout is similar to that of other salmonid fishes (Pfeiffer, 1963). The olfactory epithelium is located on the broad surfaces of 12-16 lamellae that radiate from the bases of the bilaterally paired olfactory rosettes. The pseudostratified columnar olfactory epithelium is easily distinguished from the non-sensory epithelium that covers the edge of the lamellae and the secondary folds separating the strips of sensory epithelium. A single olfactory nerve, approximately $1 \mathrm{~cm}$ long, projects from the ventral posterior region of each olfactory rosette to the ipsilateral olfactory bulb, which is directly apposed to the telencephalon. 

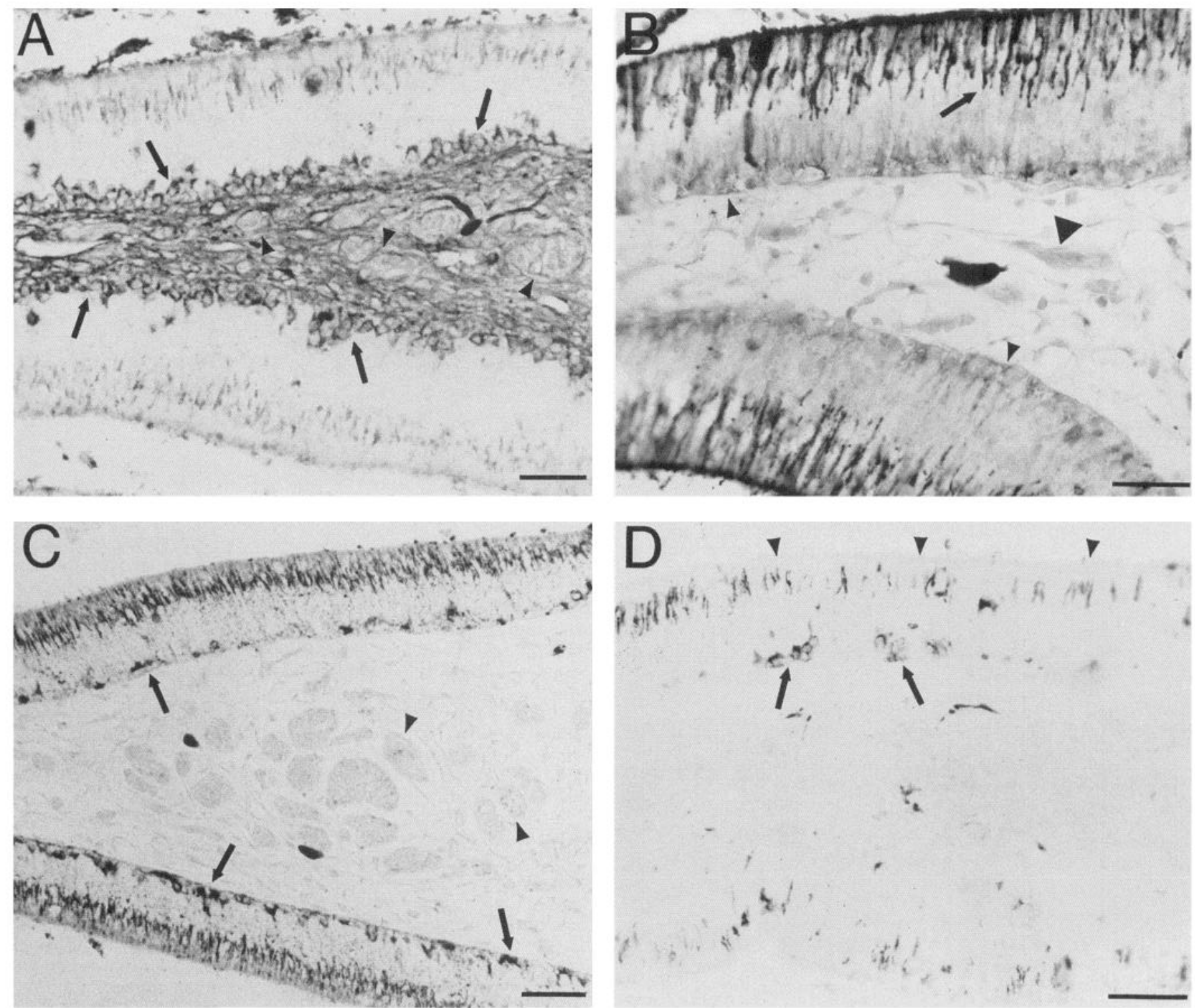

Figure 1. Lectin labeling of trout olfactory mucosa. A, Phaseolus vulgaris phytohemagglutinin (PHA). Little PHA reactivity is evident in the olfactory epithelium except in the basal layer (arrows). PHA reactivity is moderately intense in the connective tissue core of the lamella and weaker in the axonal bundles (arrowheads). B, Ulex europaeus agglutinin I (UEA I). UEA I intensely labels reactive cell processes in the apical region of the olfactory epithelium (arrow); some elements of the basal layer are also labeled (small arrowheads). Nerve fascicles are weakly labeled (large arrowhead). The large dark region in the center of the micrograph is a melanocyte, not the result of lectin binding. $C$, Soybean agglutinin (SBA). There is intense SBA reactivity in the apical region of the olfactory epithelium. Small groups of cells in the basal layer are also labeled (arrows). Within the lamellar core discrete puncta of intense SBA reactivity are apparent in some axonal bundles (arrowheads). D, Dolichos biflorus agglutinin (DBA). Distinct DBA-reactive processes are visible in the apical region of the olfactory epithelium, but the labeled processes occur in scattered clusters along the epithelium and are unlabeled near the surface of the epithelium (arrowheads). Small groups of cells in the basal layer of the olfactory epithelium are labeled by DBA (arrows); no DBA reactivity is apparent in the axonal bundles within the core of the lamella. Scale bars, $50 \mu \mathrm{m}$.

\section{Lectin labeling}

Each lectin labeled some part of the olfactory epithelium, olfactory nerve, and/or brain. The patterns of reactivity are summarized below.

Wheat germ agglutinin (WGA), concanavalin A (ConA), and peanut agglutinin (PNA). WGA and ConA labeling were ubiquitous in the olfactory epithelium, olfactory nerve, olfactory bulb, and telencephalon. Preincubation with $8 \mathrm{~mm}$ triacetylchitotriose, but not $100 \mathrm{~mm} \mathrm{~N}$-acetylglucosamine, significantly reduced reactivity to WGA (the nominal carbohydrate specific- ities of the lectins are given in Table 1). Preincubation of ConA with $100 \mathrm{~mm}$ methyl mannopyranoside eliminated most ConA reactivity.

PNA reactivity in the olfactory mucosa was apparent in mucous cells and in light labeling of bundles of olfactory axons. PNA reactivity was evident throughout the olfactory bulb and telencephalon, but was less intense in the olfactory nerve layer and glomerular layer than in other regions of the olfactory bulb. PNA binding was eliminated by preincubation with $100 \mathrm{~mm}$ lactose.

Phaseolus vulgaris phytohemagglutinin (PHA). PHA labeling 


\begin{tabular}{|c|c|c|c|}
\hline & $\begin{array}{l}\text { Highly } \\
\text { reactive }\end{array}$ & $\begin{array}{l}\text { Moderately } \\
\text { reactive }\end{array}$ & Nonreactive \\
\hline $29 \mathrm{Rt}$ & 21 & 43 & 36 \\
\hline $33 \mathrm{Lt}$ & 16 & 49 & 35 \\
\hline $34 \mathrm{Rt}$ & 22 & 38 & 40 \\
\hline $36 \mathrm{Rt}$ & 19 & 40 & 41 \\
\hline $41 \mathrm{Lt}$ & 25 & 38 & 37 \\
\hline Mean \pm SD & $21 \pm 3$ & $42 \pm 5$ & $38 \pm 3$ \\
\hline
\end{tabular}

was moderately intense in the core of the olfactory lamellae and in the non-sensory epithelium. Within the olfactory epithelium, PHA reactivity was apparent in the basal layer, where a band of globular cells adjacent to the basal lamina was labeled (Fig. $1 A$ ). PHA bound weakly to fascicles of olfactory axons in the lamellae (Fig. 1A), in the olfactory nerve, and in the olfactory bulb.

Ulex europaeus agglutinin I (UEA I). UEA I reacted with a few cells in the non-sensory epithelium and with the apical portions of many cells in the olfactory epithelium. These labeled processes extended from somata in the middle one-third of the epithelium and appeared to be evenly distributed (Fig. 1B); some ended in distinct olfactory knobs in the heavily labeled mucous layer. Fascicles of axons leaving the basal lamina, in the core of each lamella (Fig. $1 B$ ), and in the olfactory nerve and bulb were lightly labeled with UEA I. Reactive fibers were distributed throughout the glomerular layer in five of seven trout; in the other two the apparent density of labeled fibers was markedly decreased laterally. UEA I labeled cells in the granular layer of the olfactory bulb and periventricular cells throughout the telencephalon. UEA I also recognized secondary olfactory fibers in the lateral and medial olfactory tracts, as well as a fascicle of fibers that passed through the ventromedial olfactory bulb and into the ventromedial telencephalon (the telencephalopetal fascicle; Riddle and Oakley, 1992). Preincubation of UEA I with $100 \mathrm{~mm}$ L-fucose eliminated all UEA I reactivity except the labeling of cells in the granular and periventricular regions.

Soybean agglutinin (SBA). SBA bound to mucous cells and mucus within the olfactory and non-sensory epithelium and to scattered groups of cells in the basal layer of the olfactory epithelium. More intense SBA reactivity was evident in regularly distributed, spindle-shaped processes (approximately 1-2 $\mu \mathrm{m}$

Figure 2. Pokeweed agglutinin (PWA) binding in the olfactory epithelium. $A$, PWA reacted intensely with the apical portion of scattered cells in the olfactory epithelium (small arrowheads); numerous other receptor cells were labeled less intensely. Some basal cells (large arrowhead) were also reactive. PWA-positive axons were evident in small bundles near the basal lamina (open arrow) and in larger fascicles running parallel to the long axis of the lamella (solid arrow). $B$, At higher magnification, the ciliated knobs of olfactory receptor cells can be readily distinguished (arrowheads). In the intensely reactive cells the cell body and a portion of the axon were also heavily labeled (arrow). $C$, Differential interference contrast view (Nomarski) of an intensely PWA-reactive receptor cell at higher magnification. Note the characteristic olfactory knob (arrowhead) and labeled axon (small arrows). Scale bar: $45 \mu \mathrm{m}$ for $A ; 10 \mu \mathrm{m}$ for $B$ and $C$.
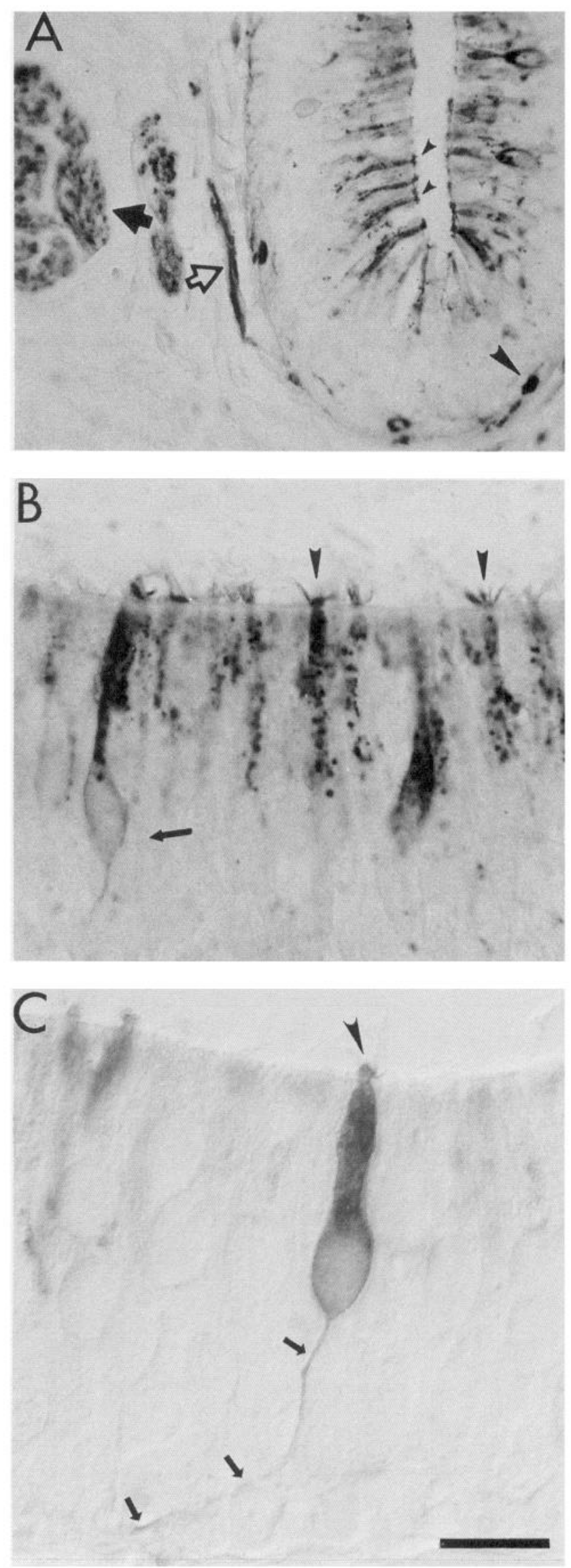


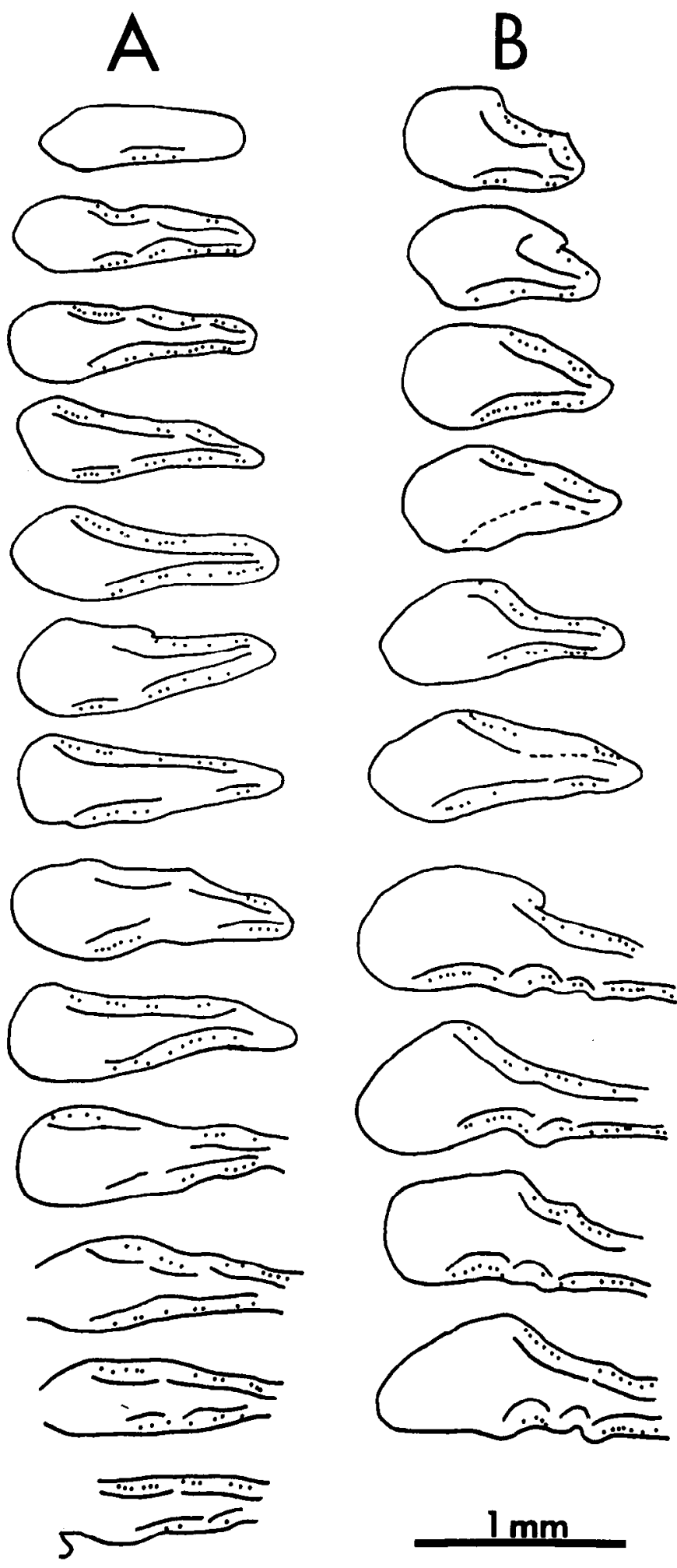

Figure 3. Distribution of PWA-reactive olfactory receptor neurons. The locations of olfactory receptor neurons extensively labeled by PWA (similar to Fig. $2 C$ ) are indicated by dots on camera lucida drawings of cross sections through two representative lamellae $(A$ and $B$ ). In each cross section those portions of the lamella covered by olfactory epithelium are underlined. In portions of two sections (dashed lines), receptor cells were cut transversely, making it difficult to distinguish extensively labeled receptor neurons at these sites. The sections are spaced at about $0.1 \mathrm{~mm}$ intervals and progress from the tip of each lamella (top of the figure) toward the basc (bottom) where the lamellae attach to the raphe of the olfactory rosette. wide) in the apical half of the olfactory epithelium (Fig. 1C). Punctate SBA reactivity was evident in many, but not all, fascicles of olfactory axons within the lamellar core (Fig. 1C), in the olfactory nerve, and in the olfactory nerve layer and glomerular layer of the olfactory bulb. SBA reactivity was particularly low in the lateral glomerular layer; in two of six animals there was no apparent labeling laterally. In contrast to UEA I, SBA did not label the olfactory tracts (although SBA did label the telencephalopetal fascicle from the olfactory nerve). Preincubation of SBA with $100 \mathrm{~mm} N$-acetylgalactosamine eliminated reactivity; preincubation with $100 \mathrm{~mm}$ galactose reduced reactivity.

Dolichos bifloris agglutinin (DBA). Compared to that of SBA, DBA reactivity was less intense at identical dilutions. Furthermore, DBA reacted with fewer cells in the basal layer and the DBA-positive apical spindles were distributed less regularly; they occurred every $1-2 \mu \mathrm{m}$ in some regions, but were separated by tens of micrometers in other areas (Fig. 1D). The apical 10 $\mu \mathrm{m}$ of the olfactory epithelium was unlabeled. Olfactory axons were generally unlabeled, although the highest concentration tested $(0.01 \% \mathrm{DBA})$ yielded faint labeling in the olfactory nerve layer and glomerular layer of the olfactory bulb. Preincubation with $100 \mathrm{mM} N$-acetylgalactosamine eliminated DBA reactivity.

Pokeweed agglutinin ( $P W A$ ) reactivity in the olfactory epithelium and nerve. PWA labeling was more consistent and robust than that of the other lectins. PWA reacted moderately with the apical processes of numerous olfactory cpithelial cells (Fig. $2 A, B$ ). These evenly distributed processes arose from somata in the middle one-third of the olfactory epithelium, and often terminated in a distinct knob (Fig. 2B). The olfactory knob and cilia, dendrite, cell body, and basally directed axon of some receptor cells were labeled more intensely by PWA (Fig. $2 C$ ). The apparent incidence of such well-labeled receptor neurons was similar bilaterally; these neurons were always widely distributed throughout the olfactory epithelium of each lamella of the olfactory rosette (Fig. 3). Reactive epithelial cells were separated by unlabeled cells, probably consisting of supporting cells and receptor cells that were not recognized by PWA (see Discussion). In addition to receptor cells, PWA labeled a few cells in the basal region of the olfactory epithelium (Fig. $2 A$ ) and scattered cells in the core of the lamellae.

PWA-reactive axons penetrated the basal lamina and combined into 2-8 $\mu \mathrm{m}$ bundlcs that joined larger fascicles running through the core of the lamella (Fig. $2 A$ ). Small puncta of intense PWA reactivity were scattered among unlabeled or modestly labeled axons in the fascicles within the core of the olfactory lamellae (Fig. 2A) and in the olfactory nerve (Fig. 4A). In longitudinal sections of the olfactory nerve, notably straight, intensely labeled strands were apparent (Fig. $4 B$ ); these dark strands were similar to the puncta in respect to their prevalence, distribution, and diameter. A few PWA-positive round cells, 6-8 $\mu \mathrm{m}$ in diameter, were evident in the olfactory nerve.

$P W A$ reactivity in the olfactory bulb. In contrast to the wide dispersion of PWA-reactive elements in both the olfactory epithelium and the olfactory nerve, PWA-positive axons in the olfactory bulb converged and terminated in subregions of the glomerular layer. In PWA-labeled sections of the olfactory bulb, the glomerular layer was divided into highly reactive, moderately reactive, and unreactive regions (Figs. 5, 6). In somc horizontal planes all three levels of reactivity were evident in a single histological section (Fig. 6A). Over much of the dorsalventral extent of the olfactory bulb, the glomerular layer was 

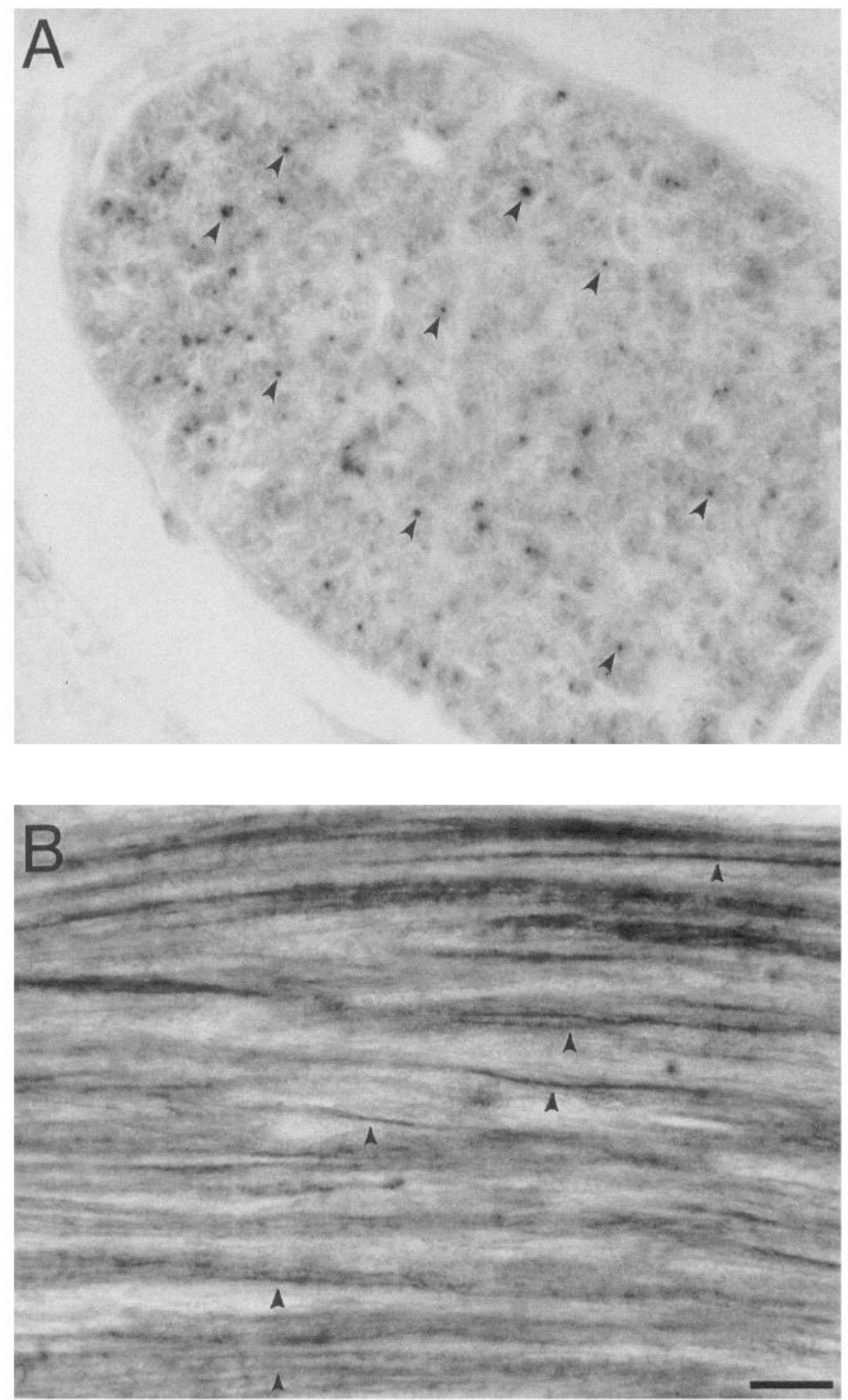

Figure 4. PWA labeling in the olfactory nerve. $A$, Numerous puncta of reaction product are evident in this representative cross section of one fascicle of the olfactory nerve, labeled with PWA. The darkest puncta (arrowheads) are scattered within a less reactive matrix of axons. The small bundles of darkly labeled axons were scattered throughout this and all other olfactory nerve fascicles; they were not restricted to particular portions of the olfactory nerve. $B$, Longitudinal sections of the olfactory nerve contained stretches of intensely reactive parallel fascicles ( $a r$ rowheads) that corresponded in size to the darkly labeled puncta observed in cross sections $(0.5-1.5 \mu \mathrm{m})$. Scale bar: $10 \mu \mathrm{m}$ for $A ; 15 \mu \mathrm{m}$ for $B$. intensely labeled ventral medially but unlabeled laterally (Fig. $5 A$ ). Even when the concentration of the lectin was increased 100 -fold over that providing clear labeling in the reactive regions (from $0.0001 \%$ to $0.01 \%$ ), olfactory axons in the lateral glomerular layer failed to bind PWA (Figs. 5A,6A). Labeling with antiserum to $\mathrm{KLH}$ revealed an abundance of $\mathrm{KLH}$-reactive axons terminating in the lateral region (Fig. $5 B$ ), indicating that a lack of olfactory axons could not explain the lack of PWA binding. Similarly, in areas of the glomerular layer in which highly PWA-reactive and moderately PWA-reactive regions were evident (Fig. 5C), anti-KLH labeling demonstrated a rather ho- mogeneous distribution of olfactory axons across the regions of differential lectin binding (Fig. 5D). Thus, variation in PWA reactivity was not simply due to quantitative differences in the density of innervation, but rather to variation in the reactivity of the axons in the different regions of the glomerular layer.

The percentage of the combined olfactory nerve layer and glomerular layer that was PWA positive was consistent across individual fish (Table 2). For five animals, $21 \pm 3 \%$ (mean \pm $1 \mathrm{SD}$ ) of the olfactory nerve layer and glomerular layer was intensely labeled by PWA, $42 \pm 5 \%$ was moderately labeled, and $38 \pm 3 \%$ was unlabeled. Consistent with the low variance 

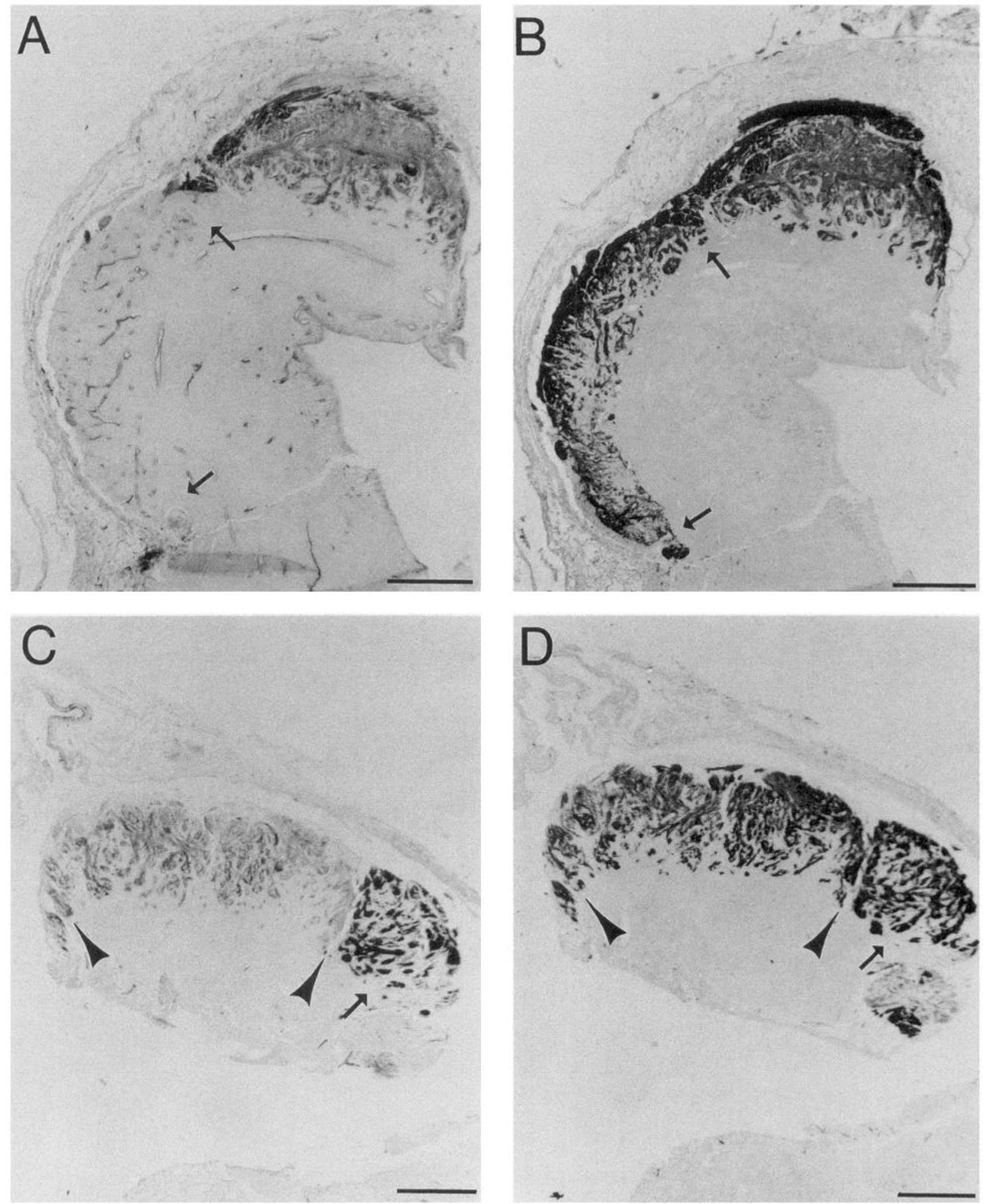

Figure 5. PWA labeling in the olfactory bulb: horizontal sections from the center $(A$ and $B)$ and dorsal $(C$ and $D)$ regions of the olfactory bulb. $A$ and $C$ were labeled with PWA, $B$ and $D$ with anti-KLH. $A$, In the left olfactory bulb no PWA-reactive axons were evident in the lateral olfactory nerve layer or glomerular layer (the region between the arrows). Blood vessels in this region are lightly labeled. B, Anti-KLH labeling of the adjacent section demonstrates that numerous primary olfactory axons innervate the lateral region that is not labeled by PWA. $C$, More dorsally in the olfactory bulb, PWA reactivity is moderate medially (between arrowheads) and intense laterally (arrow). $D$, Anti-KLH labeling of the adjacent section demonstrates similar innervation density in the medial and lateral regions. Hence, a differential abundance of axons does not account for the differential PWA labeling. Scale bars, $250 \mu \mathrm{m}$. 

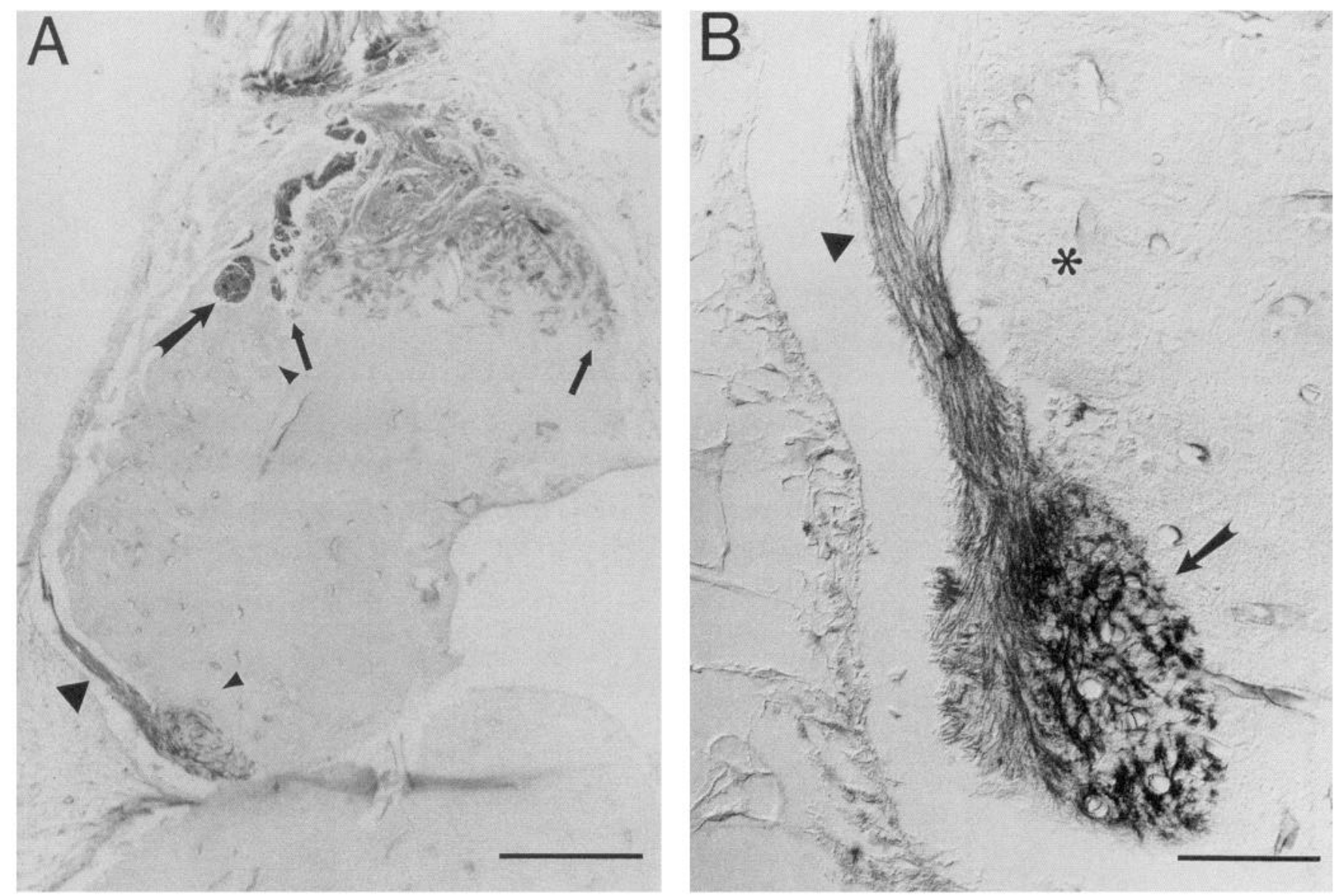

Figure 6. PWA labeling in the olfactory bulb. A, Horizontal section through the ventral portion of the olfactory bulb, labeled with PWA. Distinctly separate regions with high (large arrow), intermediate (between small arrows), and no PWA reactivity (between small arrowheads) are apparent. Note the large labeled fascicle (large arrowhead) that courses around the PWA-negative region in the lateral olfactory bulb to terminate posterior laterally. $B$, This fascicle is shown at higher magnification in the posterior lateral region of the olfactory bulb from another specimen. The fascicle (arrowhead) followed the same trajectory around the lateral glomerular layer (asterisk) and into the posterior lateral glomerular layer in every trout examined. Note that in this region of the glomerular layer the axons form nonglomerular, brush terminations (arrow), not the more typical glomerular terminations evident in other terminal fields (see Fig. 5). Scale bars: $A, 250 \mu \mathrm{m} ; B, 50 \mu \mathrm{m}$.

in these percentages, the spatial pattern of differential labeling by PWA was bilaterally symmetrical and congruent across individuals. Nine distinct terminal fields were demarcated by differential PWA reactivity within the glomerular layer (Fig. 7); the boundaries of these fields corresponded to those recognized in anti-KLH preparations (Riddle and Oakley, 1992). PWA labeling was always most intense in two of the dorsal glomerular fields, was absent in the lateral glomerular field and in the dorsal posterior lateral field, and was intermediate in the remaining five fields (Fig. 7). Each glomerular field appeared homogeneous in its PWA reactivity. In most PWA-positive regions the axon bundles ended in familiar glomerular terminations (Figs. 5, 6A), but in two regions PWA-positive axons terminated in brushlike endings (Fig. 6B; see also Riddle and Oakley, 1992).

The contrast between the substantial dispersion of PWA-positive axons in the olfactory nerve and their aggregated terminations in the glomerular layer suggested that the process of selective axonal aggregation might occur at the olfactory nervebulb interface. This was demonstrated by examining closely spaced cross sections of the posterior region of the olfactory nerve (Fig. 8). Differentially labeled fascicles became apparent in this region, forming over a longitudinal distance of 100-200 $\mu \mathrm{m}$. The juxtaposition of differentially reactive fascicles in this region was also apparent in horizontal sections. Double labeling with anti-KLH verified that the nonreactive regions between PWA-reactive fascicles contained numerous olfactory axons, not an axon-free matrix (Fig. 9). These results support the conclusion that the posterior portion of the olfactory nerve is characterized by a process of axon reassortment involving selective fasciculation into strongly PWA-positive, moderately PWApositive, and PWA-negative bundles.

In addition to reacting with a subset of olfactory axons (and the telencephalopetal fascicle labeled by UEA I and SBA), PWA bound to a few small, round cells scattered in the meninges and near the ventricles. These cells were rare in normal fish, but increased in number after brain surgery, suggesting reactive gliosis. The only other PWA reactivity in the trout brain was restricted to a narrow band of cells located in the roof of the rostral portion of the third ventricle.

The carbohydrate specificity of PWA binding was investigated by preabsorption with various sugars. PWA reactivity was unaffected by preabsorption with $100 \mathrm{mM}$ L-fucose, $\mathrm{N}$-acetylgalactosamine, or $N$-acetylglucosamine, but was eliminated completely by preincubation with $8 \mathrm{~mm}$ triacetylchitotriose. The sensitivity of PWA binding to tissue fixation was also examined. PWA binding was reduced in paraformaldehyde-fixed tissue 


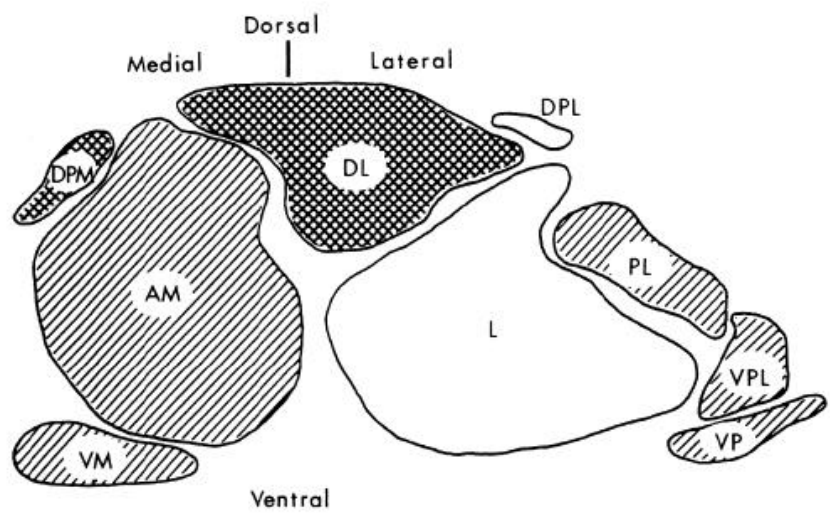

Figure 7. PWA labeling of terminal fields. PWA labeling always revealed nine distinct terminal fields in the glomerular layer: dorsal lateral $(D L)$, dorsal posterior lateral $(D P L)$, dorsal posterior medial $(D P M)$, anterior medial $(A M)$, lateral $(L)$, posterior lateral $(P L)$, ventral posterior lateral $(V P L)$, ventral medial $(V M)$, and ventral posterior $(V P)$. The terminal fields are shown here in a flattened representation projected onto a single coronal plane (for details, see Riddle and Oakley, 1992). The two terminal fields intensely labeled by PWA are cross-hatched, those fields lightly labeled by PWA are indicated by diagonal lines, and those fields unreactive to PWA are open. Scale bar, $1 \mathrm{~mm}$.

relative to that in tissue fixed in $\mathrm{HgCl}_{2}$ or ethanol/acetic acid. In studies of lectin binding, as in immunocytochemistry, the choice of fixative is an important consideration. Hempstead and Morgan (1983a) previously reported that PWA binding was limited to the luminal surface of rat olfactory epithelium fixed with paraformaldehyde. We replicated their observations in rats perfused with paraformaldehyde (data not shown). After $\mathrm{HgCl}_{2}$ or acid/alcohol fixation, however, PWA labeled most rat olfactory receptor cell neurons and axons. Thus, with suitable fixation PWA binds to non-teleostean olfactory receptor neurons; there was no evidence PWA recognized a subset of receptor cells in the rat.

\section{Effects of lesions of the olfactory system on PWA reactivity}

We lesioned the olfactory system in several trout to verify that the PWA-reactive elements in the epithelium were olfactory receptor neurons and to determine whether the normal distribution of PWA-positive axons in the olfactory bulb would be reestablished following reconstitution of the primary olfactory projection. Histological sections of the lesioned olfactory rosette and nerve of experimental animals were stained simultaneously with sections from the normal contralateral side so that tissue could be compared without concern about slight variations in histological conditions or procedures. Except where indicated, changes in PWA reactivity were limited to the side of the experimental lesion. Details of the process of reinnervation of the olfactory bulb following lesions have been reported elsewhere (Riddle and Oakley, 1992); here we report only those details specific to PWA reactivity.

Effects of olfactory nerve transection. Two to three weeks after transection of one olfactory nerve, PWA reactivity was greatly

Figure 8. PWA-reactive axons aggregate near the olfactory bulb: cross sections of the posterior olfactory nerve near the nerve-bulb interface, taken at $80 \mu \mathrm{m}$ intervals. $A$, In the most rostral section two dark telencephalopetal fascicles (small arrowheads) are apparent at low magnification. These were visible throughout the length of the nerve and continued through the olfactory bulb into the telencephalon. In some specimens the telencephalopetal projection was represented in the nerve
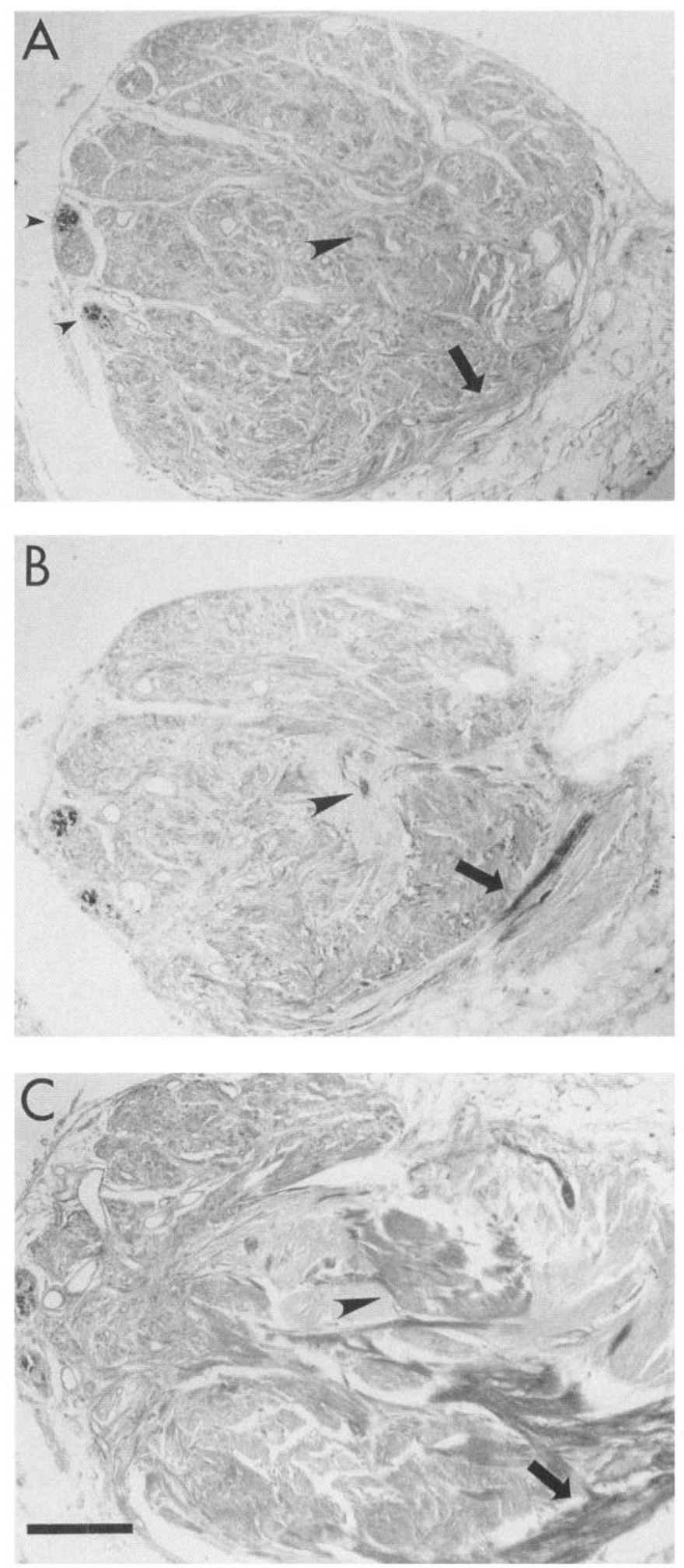

by a single bundle. In this section, and all sections more rostral, all other PWA-reactive axons were widely dispersed in small bundles like those in Figure 4. The large arrowhead and the arrow indicate the regions where distinct PWA-positive fascicles form posteriorly. B, Several prominent fascicles of darkly labeled (arrow and large arrowhead), lightly labeled, and unlabeled axons were apparent $80 \mu \mathrm{m}$ closer to the olfactory bulb. $C$, Still closer to the olfactory bulb, more and larger differentially reactive fascicles can be seen (arrow and large arrowhead). Such fascicles could be followed through the olfactory nerve layer to their terminations in the glomerular fields. Scale bar, $100 \mu \mathrm{m}$. 

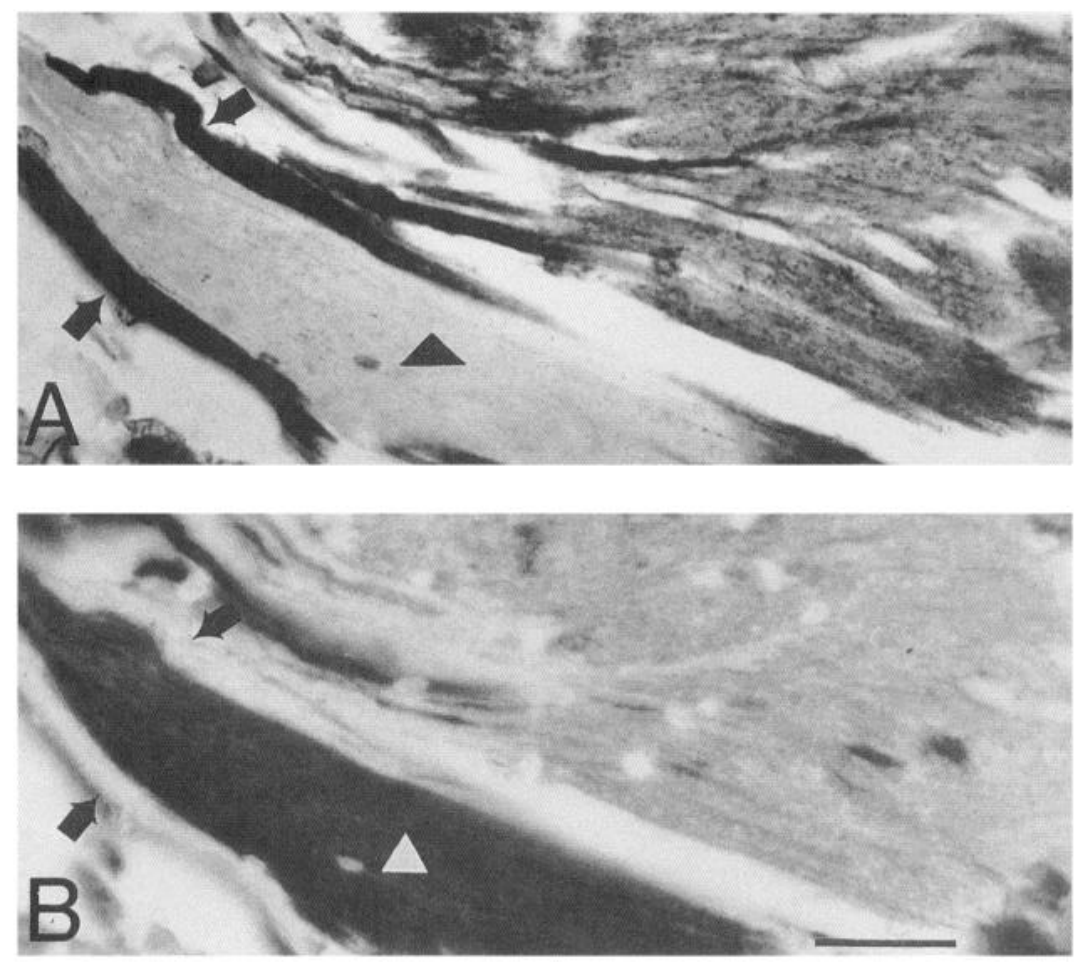

Figure 9. Double labeling with PWA and anti-KLH at the nerve-bulb interface. $A$, Two distinct fascicles of PWApositive axons (arrows) diverge as they enter the olfactory bulb. The intervening tissue is PWA negative (triangle). PWA binding was visualized by the peroxidase-DAB reaction. $B$, Labeling the same section with antiserum to KLH and an FITC-labeled goat anti-rabbit secondary antibody revealed that the intervening PWA-negative tissue consisted of numerous olfactory axons (white triangle). The fact that the PWApositive fascicles (arrows) appear unlabeled in $B$ is a consequence of the $\mathrm{DAB}$ reaction product blocking the fluorescence of the FITC label on the PWA-positive axons. With two fluorescent markers it was evident that all axons were KLH positive. Scale bar, 40 $\mu \mathrm{m}$. reduced in the ipsilateral olfactory rosette ( $N=3$ fish; Fig. 10). No labeled olfactory knobs or extensively labeled receptor cells remained, although a few lightly reactive processes were evident. The incidence of PWA-positive cells in the basal layer of the olfactory epithelium increased in both the ipsilateral and contralateral mucosae. By 4-6 weeks after nerve transection a few extensively labeled receptor cells were evident in the olfactory epithelium on the lesioned side; the control rosette appeared normal $(N=4)$. The intensity of PWA reactivity in the apical olfactory epithelium and the incidence of extensively labeled receptor cells increased substantially with longer survival periods; by 14 weeks after nerve transection PWA reactivity was similar in the experimental and control mucosae $(N=2)$.

Changes in PWA reactivity in the ipsilateral olfactory nerve paralleled those in the olfactory epithelium. The intensity of PWA reactivity was greatly reduced throughout the olfactory nerve at 2, 4, and 6 weeks after transection, and virtually no darkly labeled axons were present (Fig. 11). The intensity of PWA reactivity increased by 14 weeks after the lesion.

By 2-4 weeks after nerve transection the PWA-reactive axons disappeared from the ipsilateral olfactory bulb (Fig. 12A), except for a small group of glomeruli that remained in the ventral medial bulb. PWA-labeled fibers gradually reappeared in the olfactory bulb, and were always restricted to those regions of the olfactory bulb that were PWA positive in the normal olfactory bulb. At 14 weeks after nerve transection the density of stained axons remained below that in the control olfactory bulb (Fig. 12B,C), but PWA-positive axons traveled to, and terminated in, their normal loci.

Effects of bulbectomy. The reduction in PWA reactivity in the olfactory epithelium and nerve after olfactory bulbectomy was similar to that observed after comparable survival periods following nerve transection. Reactivity was largely absent 2-3 weeks after bulbectomy $(N=3)$, but there were extensively labeled receptor cells in the epithelium and reactive puncta in the ol- factory nerve by 5 weeks after bulbectomy $(N=2)$. The regenerating olfactory nerve fascicles were PWA positive even after bilateral bulbectomy $(N=4)$ and after bulbectomy and insertion of a glass plate to discourage olfactory nerve regeneration into the brain $(N=2)$. These findings suggest that contact with the olfactory bulb was not required for expression of the PWA binding site(s).

Effects of olfactory rosette extirpation. Trout were killed $6(\mathrm{~N}$ $=2)$ and $12(N=1)$ weeks after extirpation of one olfactory rosette. In all three fish, PWA reactivity was eliminated from the ipsilateral olfactory nerve except for a few small reactive cells; no PWA-reactive fibers were evident in the ipsilateral olfactory bulb.

\section{Discussion}

Cell surfaces are decorated with a rich assortment of carbohydrates (Cook, 1986), which may encode substantial biological information (Sharon, 1980). There is evidence that cell surface carbohydrates mediate a variety of cellular interactions and that functionally significant subsets of sensory neurons can be identified on the basis of the carbohydrate-containing molecules they bear (reviewed in Jessell et al., 1990). Since lectins are specific for particular carbohydrate moieties, they can be used to survey the distribution of glycoconjugates within tissues. Hence, in the present study we used lectins to identify subclasses of olfactory receptor neurons and to evaluate the pattern of their projections to the olfactory bulb. Lectins can be divided into six major groups based upon the class of carbohydrate that they bind (Sharon and Lis, 1989). We tested lectins from each of these groups: $N$-acetylgalactosamine (SBA and DBA), galactose (PNA), mannose/glucose (ConA), L-fucose (UEA I), $N$-acetylglucosamine (PWA and WGA), and $\mathrm{N}$-acetylneuraminic acid (WGA), as well as one lectin with complex binding specificity (PHA). The availability of a method (anti-KLH labeling) to visualize the entire olfactory projection in a manner that was compatible 
Figure 10. Effects of olfactory nerve transection on PWA reactivity in the olfactory mucosa: cross sections through lamellae from the contralateral $(A)$ and ipsilateral $(B)$ olfactory rosettes 3 weeks after unilateral olfactory nerve transection. $A$, As in normal animals, PWA reactivity is apparent in the apical region of the olfactory epithelium $(O E)$ and in the axonal bundles in the core of the lamella (large arrows). There appear to be more PWA-positive cells in the basal layer of the epithelium (small arrows) than in normal mucosae. $B$, PWA reactivity was substantially reduced in the ipsilateral olfactory rosette after nerve transection. Except for the many PWA-reactive cells in the basal layer (small arrows), PWA labeling in the olfactory epithelium was eliminated 3 weeks after nerve transection. Labeling was also absent from the nerve fascicles in the lamellar core (large arrows). As in normal mucosae, some PWA-positive cells are scattered within the core of the lamella. Scale bar, 100 $\mu \mathrm{m}$.
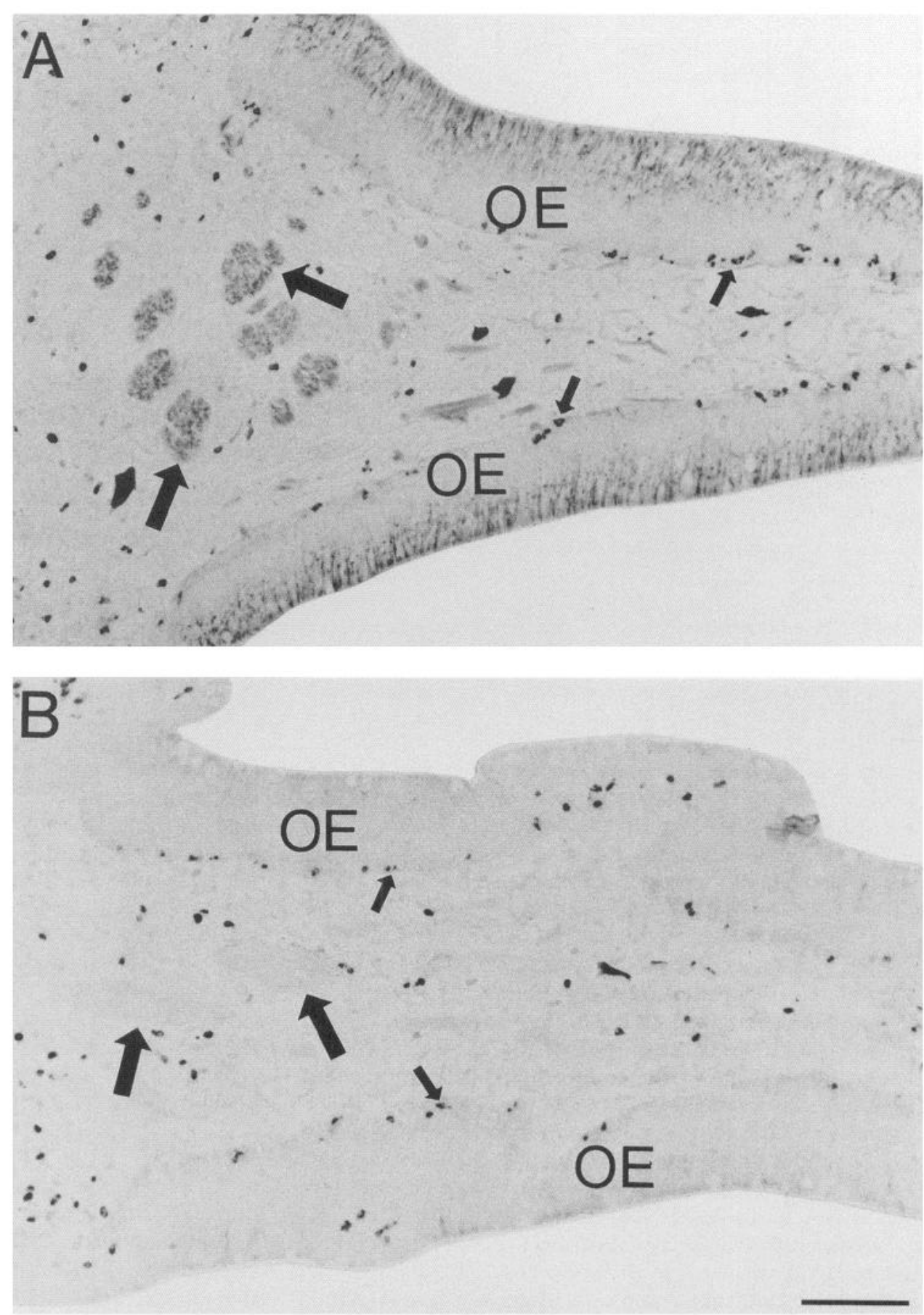

with lectin labeling allowed us to determine easily (1) which lectins bound to olfactory receptor cells and their axons, (2) whether all or a subset of receptor cells was recognized, and (3) how the lectin-positive axons were organized within the primary olfactory system. The results indicate that populations of olfactory receptor neurons vary significantly in their carbohydrate "signature" and that biochemically identified subsets of receptor neurons have distinctive projections to the olfactory bulb.

Three of the eight lectins we tested (ConA, WGA, and PNA) did not react selectively with cells in the olfactory system. The pattern of PHA labeling was more interesting; PHA reacted only modestly with mature olfactory receptor neurons and their pro- cesses but labeled cells in the basal layer of the olfactory epithelium that may have been neuronal precursors. This pattern of reactivity suggests the presence of a developmentally regulated binding site for PHA. Several investigators have demonstrated that differentiating neurons in other systems can be identified on the basis of oligosaccharide expression (Levine et al., 1984; Yamamoto et al., 1985; Constantine-Paton et al., 1986; Blum and Barnstable, 1987; Schwarting et al., 1987).

The reaction of the remaining four lectins with subsets of olfactory receptor cells indicates that olfactory receptor neurons vary significantly in the carbohydrate-containing molecules that they bear. Three of the four lectins-UEA I, SBA, and DBA- 
were previously demonstrated to react with olfactory receptor neurons and their axons in other vertebrates (Key and Giorgi, 1986a,b; Plendl and Schmahl, 1988; Barber, 1989).

We found that most or all receptor cells and supporting cells in the olfactory epithelium bound UEA I. Consistent with this, all glomerular fields in five of seven trout had UEA I-reactive axons, indicating that UEA I bound to all olfactory axons or at least to a subset that was distributed throughout the glomerular layer. In two trout, however, there was regional heterogeneity in UEA I binding, somewhat like that previously described in the rat (Barber, 1989). The reasons for the inconsistency between individual trout in the pattern of UEA I labeling remain unclear.

The lectins SBA and DBA have the same nominal carbohydrate affinity but produced somewhat different patterns of labeling. In the olfactory epithelium there was little DBA reactivity over the apical portion of receptor cell dendrites, an area intensely labeled by SBA; and DBA-reactive receptor neurons appeared to be distributed less regularly than those labeled by SBA. In the olfactory bulb (where little, if any, DBA labeling was apparent) SBA labeled a subset of olfactory axons that was similar, but not identical, to the subset recognized by PWA. Differences included a cluster of axons terminating in the posterior lateral glomerular layer that was highly reactive to PWA but was not labeled by SBA. In addition, SBA-reactive axons in the lateral glomerular layer did not bind PWA even at high concentrations. Within the several other glomerular fields reactive to both PWA and SBA we could not determine whether individual axons expressed both binding sites.

PWA most effectively and clearly distinguished subclasses of olfactory receptor cells and their processes at all levels of the trout primary olfactory system. In the olfactory epithelium, extensively PWA-labeled cells (Fig. 2C) were morphologically identical to ciliated olfactory receptor cells in teleosts as demonstrated by retrograde tracing methods (Muller and Marc, 1984; Riddle and Oakley, 1991), histochemical staining for phospholipids (Evans and Hara, 1977), and electron microscopy (Rhein et al., 1981; Zielinski and Hara, 1988). The less extensively labeled processes in the apical epithelium also belonged to receptor neurons, since each bore a distinct olfactory knob or closely resembled the more recently described type II ciliated receptor cell (Muller and Marc, 1984; Riddle and Oakley, 1992). The transient loss of PWA reactivity following olfactory nerve transection or bulbectomy provided additional evidence that the labeled elements were olfactory receptor cells. PWA binding was not, however, present in all olfactory receptor neurons. Using Nomarski optics, we could resolve receptor cells (identified by dendritic morphology and the position of the nucleus) that appeared to be unreactive. Thus, PWA failed to bind to an indeterminate fraction of olfactory receptor cells in the epithelium. A specific marker for supporting cells in teleosts, like that described in rats (Hempstead and Morgan, 1983b), would help to distinguish unreactive supporting cells from unreactive receptor cells. Anti-KLH was not helpful in this regard since it reacts with both supporting and receptor cells.

In the olfactory nerve, many intensely PWA-labeled strands of axons stood out against a background of lightly reactive and/ or unreactive axons. This PWA reactivity was lost transiently after olfactory nerve transection and permanently after removal of the olfactory rosette. The olfactory nerve is structurally quite homogeneous, consisting almost exclusively of approximately $10^{7}$ thin, unmyelinated axons bound into glial domains of groups of 50-300 axons (Kreutzberg and Gross, 1977; D. R. Riddle

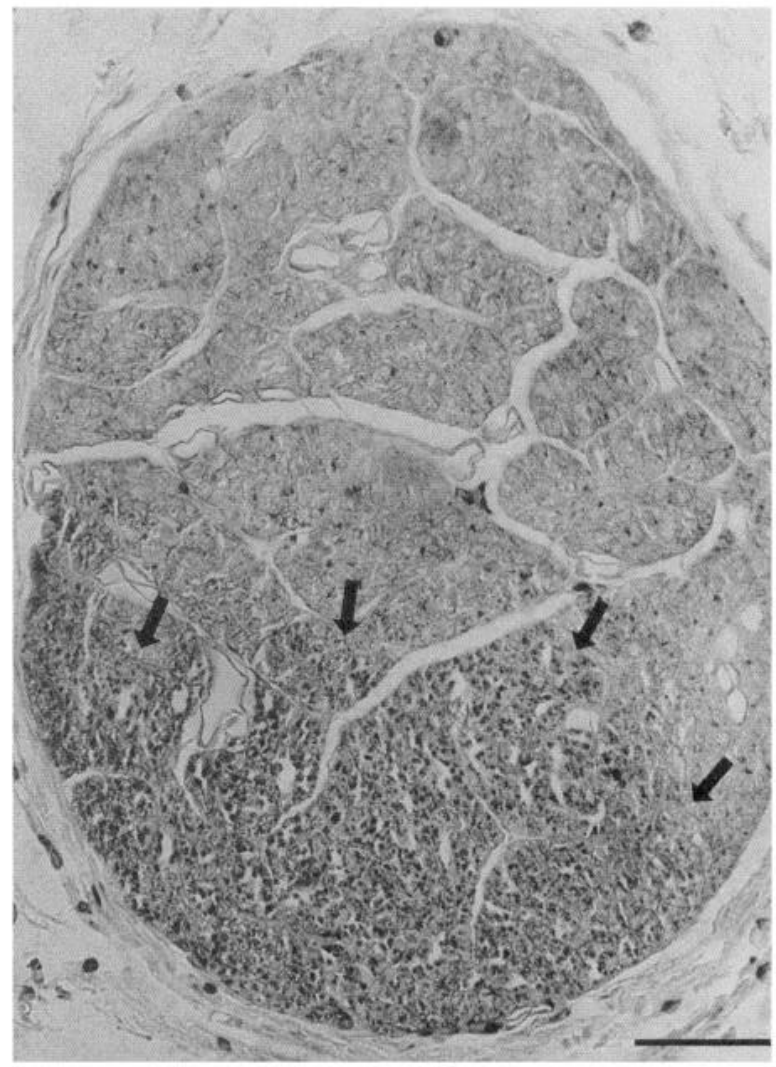

Figure 11. Effects of olfactory nerve transection on PWA reactivity in the olfactory nerve. The effects of olfactory nerve transection are evident in this cross section from an olfactory nerve that was partially transected 4 weeks earlier. The normal punctate PWA reactivity is apparent in the intact portion of the nerve (bottom), but the reactivity has been lost from the lesioned portion of the nerve (top). Note the sharp boundary between the intact and lesioned portions of the nerve (arrows). Scale bar, $50 \mu \mathrm{m}$.

and B. Oakley, unpublished observations). The PWA-positive puncta evident in cross sections were much smaller than glial cell nuclei. The strands of PWA-positive axons in longitudinal sections of the nerve were also smaller than the glially defined fascicles. Thus, it appears that within such a fascicle both PWApositive and PWA-negative bundles of axons may be found.

The delineation of a receptor neuron subclass by PWA was most obvious in the olfactory bulb, where the labeled axons were spatially segregated. Labeling the same or adjacent sections with PWA and anti-KLH indicated that some regions of the glomerular layer were innervated by PWA-negative olfactory axons, some regions by modestly PWA-reactive axons, and some regions by intensely PWA-reactive axons. The boundaries between differentially labeled regions appeared to be absolute; specifically, intensely and moderately PWA-reactive fascicles were not intermingled in the glomerular fields. It must be noted, however, that individual unlabeled axons could have been missed in the PWA-positive regions since the $0.2 \mu \mathrm{m}$ modal diameter of olfactory axons (Kreutzberg and Gross, 1977; Riddle and Oakley, unpublished observations) is at the limit of resolution of light microscopy. Thus, it is technically possible that the moderately labeled regions resulted from an intimate blend of strongly PWA-reactive and unreactive axons. It seems more likely, however, that the intensely reactive and moderately reactive regions of the glomerular layer reflect differential axon 

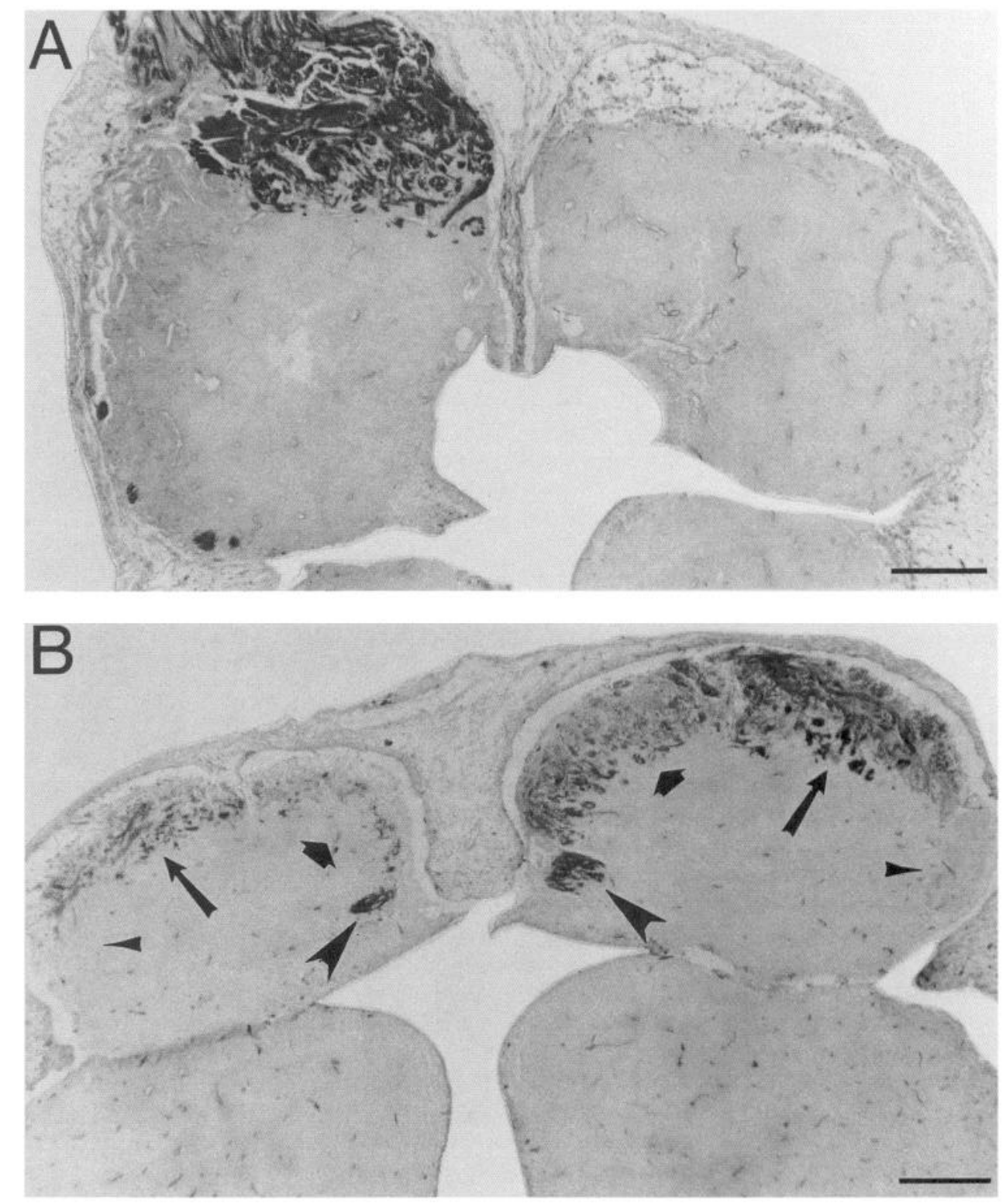

Figure 12. Effects of olfactory nerve degeneration and reconstitution on PWA reactivity in the olfactory bulb. $A$, Horizontal section through the ventral olfactory bulb 4 weeks after unilateral (right) olfactory nerve transection. PWA reactivity was eliminated from the right olfactory bulb. $B$ and $C$, Fourteen weeks after unilateral (left) nerve transection, PWA-reactive axons are apparent in the ipsilateral olfactory bulb. PWA-reactive axons were found in the regions of the glomerular layer in which they are normally located, for example, posterior medially (large arrowheads in $B$ ), dorsal laterally (long arrows in B), and dorsal medially (short arrows in $B$ and $C$ ). As in the control bulb, PWAreactive axons are absent from the lateral glomerular layer (small arrowheads in $B$ and $C$ ). Scale bars, $250 \mu \mathrm{m}$.

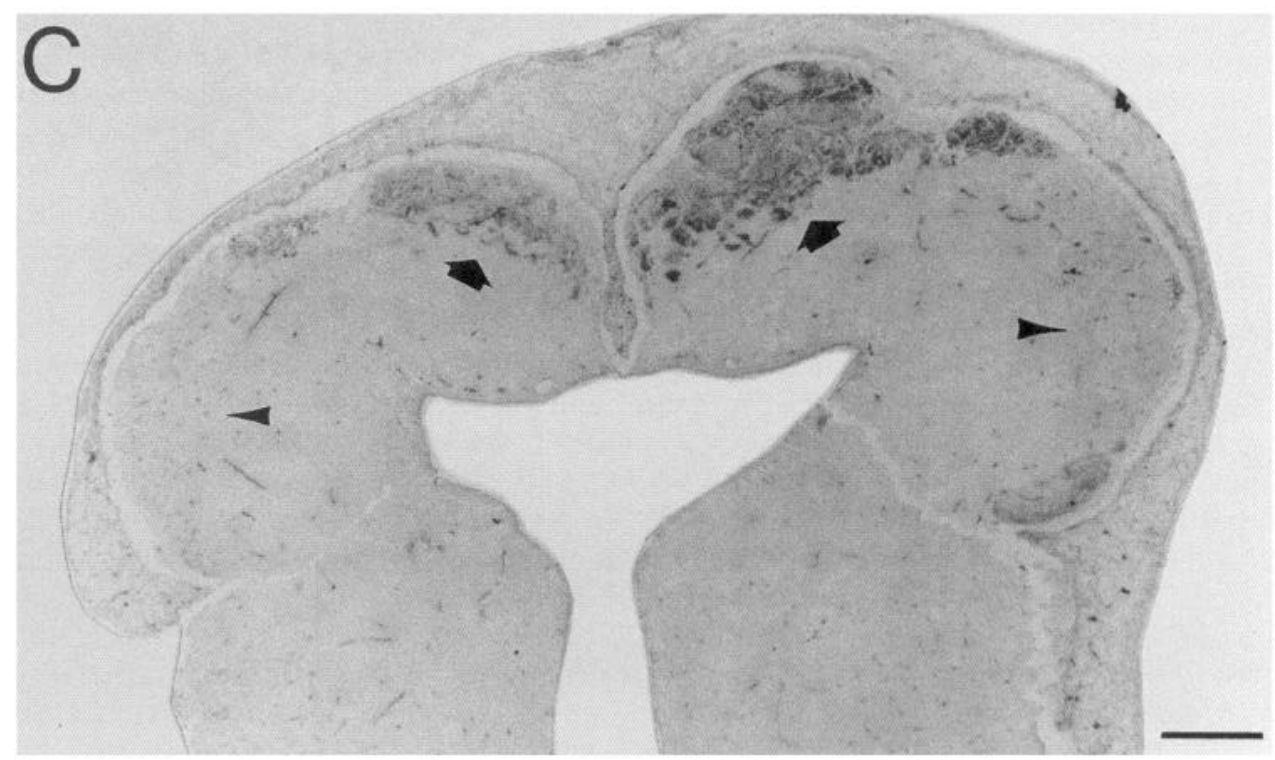


reactivity corresponding to the intensely and moderately reactive receptor neurons in the olfactory epithelium. Moderately reactive receptor cells predominated in the olfactory epithelium, consistent with the observation that the largest fraction of the glomerular layer was moderately PWA reactive. Given the difficulty in distinguishing unreactive receptor cells from supporting cells, we made no attempt to quantify the absolute fraction of receptor cells that were intensely reactive, moderately reactive, and unreactive to PWA. While we could not trace unreactive and moderately reactive axons from the epithelium to the olfactory bulb, as we could for the intensely reactive axons, the appearance of unreactive, moderately reactive, and intensely rcactive fascicles at the intcrfacc of the olfactory nerve and bulb and their continuation into restricted regions of the glomerular layer support the inference that PWA labeling distinguishes three distinct classes of olfactory receptor neurons, each with discrete central projections.

We know little about the mechanisms that result in the aggregation of subsets of olfactory axons; however, conspicuous aggregation of PWA-positive axons occurred only as the axons neared the olfactory bulb. This abrupt fasciculation of differentially labeled axons at the nerve-bulb interface suggests the presence of highly localized signals for aggregation and, perhaps, also cues that guide fascicles into selected glomerular fields.

In mammals, various lectins and monoclonal antibodies have delineated restricted projections to the olfactory bulb. For example, SBA in rat (Key and Giorgi, 1986a) and the monoclonal antibodies RB-8 in rat (Schwob and Gottlieb, 1986) and R4B12 in rabbit (Fujita et al., 1985; Mori et al., 1985) reveal dorsal and ventral projection zones in the olfactory bulb. Such studies have been important in moving the study of primary olfactory projections from the analysis of the spatial relationship between olfactory epithelium and bulb to the study of projections based on biochemical specificity. Our results with PWA as a molecular marker for subsets of trout olfactory receptor neurons differ from these earlier findings in three regards. First, the distribution pattern of differentially labeled axons in the trout olfactory bulb was not a simple regional dichotomy. Some PWA-positive glomerular fields were separated by PWA-negative fields (Figs. 7, 8). Second, the boundaries between PWA-positive and -negative regions were absolute; there was no transitional zone similar to that described for R4B12 and RB-8 staining in the main olfactory bulb of the rabbit and rat (Fujita et al., 1985; Mori et al., 1985; Schwob and Gottlieb, 1986), nor did we see PWA-positive glomeruli in PWA-ncgative glomerular fields. In mammals, R4B12, RB-8, and SBA stain a few glomeruli in negative zones and fail to react with other glomeruli in positive zones. Third, the results with PWA have demonstrated that axons with chemical commonalities can aggregate and project to discrete terminal fields, even though those axons were scattered widely within the olfactory epithelium and nerve. Thus, the projection pattern is not associated with regional topography. Since trout lack topographic projections, other reasons for the segregated projections may be considered; it is tempting to speculate that the segregation reflects the convergent projections of axons that respond to related odorants. Such a relationship between selective expression of carbohydrate-containing molecules and functional specificity has been demonstrated previously for primary sensory neurons in the rat (Dodd and Jessell, 1985). The discrete projections of the PWA-reactive neurons in the trout olfactory bulb will facilitate studies of their response properties.

Comparison of our results regarding the organization of the olfactory system in the trout with what is known about the olfactory system in amphibians and mammals raises the general issue of whether the teleostean olfactory system is organized in a manner that is fundamentally different from that in the other vertebrate classes. There are of course commonalties such as the segregation of chemically similar axons into discrete regions of the glomerular layer. The greatest difference appears to be the apparent absence of topography in the primary olfactory projection in trout, compared to the regional topography described in amphibians and mammals. It is worthwhile to exemplify what is meant by "regionally" topographic. Astic and colleagues (Astic and Saucier, 1986; Saucier and Astic, 1986; Astic et al., 1987) analyzed the projections to eight discrete projection zones, of approximately equal size, in the olfactory bulb of the rat. They concluded that the dorsal, ventral, medial, and lateral regions of the epithelium generally project to the homologous regions of the olfactory bulb, and that the anteriorposterior axis of the epithelium is mapped predominantly along the dorsal-ventral axis of the bulb. There was significant overlap in the projections. For example, our analysis of one of their published figures (Astic et al., 1987, Fig. 1) indicates that the portion of the olfactory epithelium projecting to each of the eight zones ranges from $13 \%$ (to the dorsal zone) to over $60 \%$ ( $62 \%$ to the dorsal medial zone and $63 \%$ to the medial zone). Twenty-three percent of the epithelial area projected to no more than one bulbar zone, while $28 \%$ projected to two zones, $40 \%$ to three zones, $6 \%$ to four zones, and the remaining $3 \%$ to five of the eight zones. The projection of a given epithelial region to multiple bulbar zones precludes any strict topographic organization. The regional topography described in the rat (Astic and Saucier, 1986; Saucier and Astic, 1986; Astic et al., 1987) is similar to that reported for other mammals (Le Gros Clark, 1951; Land et al., 1970; Land, 1973; Land and Shepherd, 1974; Costanzo and O'Connell, 1978; see also Kauer, 1987; Shepherd, 1991). Further understanding of the chemotopic organization of the vertebrate olfactory bulb should clarify the significance of regionally topographic projections, and their lack, for coding odor information.

In summary, lectin binding reveals chemically identifiable subsets of olfactory receptor neurons in trout that are intermingled and widely distributed peripherally, yet have segregated terminations in the glomerular layer of the olfactory bulb. Thus, while it is clear that the primary olfactory projection in trout is not organized topographically (Riddle and Oakley, 1991), there is substantial spatial order revealed by the biochemical properties of the terminating axons. The functional significance of this projection pattern, as well as the mechanisms responsible for the development and maintenance of the segregated projections, should be fruitful areas for future research.

\section{References}

Akeson RA (1988) Primary olfactory neuron subclasses. In: Molecular neurobiology of the olfactory system (Margolis FL, Getchell TV, eds), pp 269-296. New York: Plenum.

Allen WK. Akeson R (1985a) Identification of an olfactory receptor neuron subclass: cellular and molecular analysis during development. Dev Biol 109:393-401.

Allen WK, Akeson R (1985b) Identification of a cell surface glycoprotein family of olfactory receptor neurons with a monoclonal anlibody. J Neurosci 5:282-296.

Astic L, Saucier D (1986) Anatomical mapping of the neuroepithelial projection to the olfactory bulb in the rat. Brain Res Bull 16:445454.

Astic L, Saucier D, Holley A (1987) Topographical relationships be- 
tween olfactory receptor cells and glomerular foci in the rat olfactory bulb. Brain Res 424:144-152.

Barber PC (1989) Ulex europeus I agglutinin binds exclusively to primary olfactory receptor neurons in the rat nervous system. Neuroscience 30:1-9.

Blum AS, Barnstable CJ (1987) $O$-acetylation of a cell-surface carbohydrate creates discrete molecular patterns during neural development. Proc Natl Acad Sci USA 84:8716-8720.

Buck L, Axel R (1991) A novel multigene family may encode odorant receptors: a molecular basis for odor recognition. Cell 65:175-187.

Constantine-Paton M, Blum AS, Mendez-Olero R, Barnstable CJ (1986) A cell surface molecule distributed in a dorso-ventral gradient in the perinatal rat retina. Nature 324:459-461.

Cook GMW (1986) Cell surface carbohydrates: molecules in search of a function? J Cell Sci [Suppl] 4:45-70.

Costanzo RM, O'Connell RJ (1978) Spatially organized projections of hamster olfactory nerves. Brain Res 139:327-332.

Cunningham AM, Levy NS, Ryugo DK, Reed RR (1992) Patterns of expression of putative olfactory receptors. Soc Neurosci Abstr 18: 596.

Dodd J, Jessell TM (1985) Lactoseries carbohydrates specify subsets of dorsal root ganglion neurons projecting to the superficial dorsal horn of rat spinal cord. J Neurosci 5:3278-3294.

Doving KB (1990) Scent trailing by dogs. What is the physiological basis for concentration coding? In: Chemosensory information processing (Schild D, ed), pp 271-276. Berlin: Spinger.

Døving KB, Selset R, Thommesen G (1980) Olfactory sensitivity to bile acids in salmonid fishes. Acta Physiol Scand 108:123-131.

Edwards DA, Mather RA, Dodd GH (1988) Spatial variation in response to odorants on the rat olfactory epithelium. Experientia 44: 208-211.

Evans RE, Hara TJ (1977) Histochemical localization of phospholipids in the olfactory epithelium of fish. Can J Zool 55:776-781.

Fujita SC, Mori K, Imamura K, Obata K (1985) Subclasses of olfactory receptor cells and their segregated central projections demonstrated by a monoclonal antibody. Brain Res 326:192-196.

Hempstead JL, Morgan JI (1983a) Fluorescent lectins as cell-specific markers for the rat olfactory epithelium. Chem Senses 8:107-120.

Hempstead JL, Morgan JI (1983b) Monoclonal antibodies to the rat olfactory sustentacular cell. Brain Res 288:289-295.

Hempstead JL, Morgan JI (1985a) A panel of monoclonal antibodies to the rat olfactory epithelium. J Neurosci 5:438-449.

Hempstead JL, Morgan JI (1985b) Monoclonal antibodies reveal novel aspects of the biochemistry and organization of olfactory neurons following unilateral olfactory bulbectomy. J Neurosci 5:2382-2387.

Jessell TM, Hynes MA, Dodd J (1990) Carbohydrates and carbohydratc-binding proteins in the nervous system. Annu Rev Neurosci $13: 227-255$.

Jourdan F (1982) Spatial dimension in olfactory coding: a representation of the 2-deoxyglucose patterns of glomerular labeling in the olfactory bulb. Brain Res 240:341-344.

Jourdan F, Duveau A, Astic L, Holley A (1980) Spatial distribution of $\left[{ }^{14} \mathrm{C}\right] 2$-deoxyglucose uptake in the olfactory bulbs of rats stimulated with two different odours. Brain Res 188:139-154.

Kauer JS (1981) Olfactory receptor cell staining using horseradish peroxidase. Anat Rec 200:331-336.

Kauer JS (1987) Coding in the olfactory system. In: Neurobiology of taste and smell (Finger TE, Silver WL, eds), pp 151-178. New York: Wiley.

Kauer JS, Senseman DM, Cohen LB (1987) Odor-elicited activity monitored simultancously from 124 regions of the salamander olfactory bulb using a voltage sensitive dye. Brain Res 418:255-261.

Kauer JS, Neff SR, Hamilton KA, Cinelli AR (1991) The salamander olfactory pathway: visualizing and modeling circuit activity. In: Olfaction: a model system for computational neuroscience (Davis JL, Eichenbaum H, eds), pp 43-68. Cambridge, MA: MIT Press.

Key B, Giorgi PP (1986a) Soybean agglutinin binding to the olfactory systems of the rat and mouse. Neurosci Lett 69:131-136.

Key B, Giorgi PP (1986b) Selective binding of soybean agglutinin to the olfactory system of Xenopus. Neuroscience 18:507-515.

Kleerkoper $\mathrm{H}$ (1982) The role of olfaction in the orientation of fishes. In: Chemoreception in fishes (Hara TJ, ed), pp 201-225. Amsterdam: Elsevier.

Kreutzberg GW, Gross GW (1977) General morphology and axonal ultrastructure of the olfactory ncrve of the pike, Esox lucius. Cell Tissue Res 181:443-457.
Land LJ (1973) Localized projections of olfactory nerves to rabbit olfactory bulb. Brain Res 63:153-166.

Land LJ, Shepherd GM (1974) Autoradiographic analysis of olfactory receptor projections in the rabbit. Brain Res 70:506-510.

I and I J, Fager RP, Shepherd GM (1970) Olfactory nerve projections to the olfactory bulb in rabbits: demonstration by means of a simple ammoniacal silver degeneration method. Brain Res 23:250-254.

Le Gros Clark WE (1951) The projection of the offactory cpithclium on the olfactory bulb in the rabbit. J Neurol Neurosurg Psychiatry 14:1-10.

Levine JM, Beasley L, Stallcup WB (1984) The D1.1 antigen: a cell surface marker for germinal cells of the central nervous system. J Neurosci 4:820-831.

Mackay-Sim A, Shaman P, Moulton DG (1982) Topographic coding of olfactory quality: odorant-specific patterns of epithelial responsivity in the salamander. J Neurophysiol 48:584-596.

Morgan JI (1988) Monoclonal antibody mapping of the rat olfactory tract. In: Molecular neurobiology of the olfactory system (Margolis FL, Getchell TV, eds), pp 269-296. New York: Plenum.

Mori K (1987) Monoclonal antibodies (2C5 and 4C9) against lactoseries carbohydrates identify subsets of olfactory and vomeronasal receptor cells and their axons in the rabbit. Brain Res 408:215-221.

Mori K, Fujita SC, Imamura K, Obata K (1985) Immunohistochemical study of subclasses of olfactory nerve fibers and their projections to the olfactory bulb in the rabbit. J Comp Neurol 242:214-229.

Mori K, Imamura I, Onada N (1990) Signal processing in the rabbit olfactory bulb. In: ISOT $X$, Proceedings of the 10th International Symposium on Olfaction and Taste (Døving KB, ed), pp 134-141. Oslo: GCS A/S.

Muller JF, Marc RE (1984) Three distinct morphological classes of receptors in fish olfactory organs. J Comp Neurol 222:482-495.

Mustaparta $H$ (1971) Spatial distribution of receptor responses to stimulation with different odors. Acta Physiol Scand 82:154-166.

Pfeiffer W (1963) Morphology of the olfactory organ in Pacific salmon (Oncorhyncus). Can J Zool 41:1233-1236.

Plendl J, Schmahl W (1988) Dolichos biflorus agglutinin: a marker of the developing olfactory system in the NMRI-mouse strain. Anat Embryol (Berl) 177:459-464.

Rhein LD, Cagan RH, Orkand PM, Dolack MK (1981) Surface specializations of the olfactory epithelium of rainbow trout, Salmo gairdneri. Tissue Cell 13:577-587.

Riddle DR, Oakley B (1991) Evaluation of projection patterns in the primary olfactory system of rainbow trout. J Neurosci 11:3752-3762.

Riddle DR, Oakley B (1992) Immunocytochemical identification of primary olfactory afferents in rainbow trout. J Comp Neurol 324: 575-589.

Royet JP, Sicard G, Souchier C, Jourdan F (1987) Specificity of spatial patterns of glomerular activation in the mouse olfactory bulb: computer assisted image analysis of 2-deoxyglucose autoradiograms. Brain Res 417:1-11.

Saucier D, Astic L (1986) Analysis of the topographical organization of olfactory epithelium projections in the rat. Brain Res Bull 16:455462.

Schwarting GA, Jungwalla FB, Chon DKH, Boyer AM, Yamamoto M (1987) Sulfated glucuronic acid-containing glycoconjugates are temporally and spatially regulated antigens in the developing mammalian nervous system. Dev Biol 120:65-76.

Schwob JE, Gottlieb DI (1986) The primary olfactory projection has chemically distinct zones. J Neurosci 6:3393-3404.

Sharon N (1980) Carbohydrates. Sci Am 243:90-114.

Sharon N, Lis H (1989) Lectins. London: Chapman and Hall.

Sharp FR, Kauer JS, Shepherd GM (1973) Local sites of activityrelated glucose metabolism in rat olfactory bulb during olfactory stimulation. Brain Res 98:596-600.

Shepherd GM (1991) Computational structure of the olfactory system. In: Olfaction: a model system for computational neuroscience (Davis JL, Eichenbaum H, eds), pp 3-42. Cambridge, MA: MIT Press.

Shinoda K, Shiotani Y, Osawa Y (1989) "Necklace olfactory glomeruli" form unique components of the rat primary olfactory system. J Comp Neurol 284:362-373.

Skeen LC (1977) Odor-induced patterns of deoxyglucose consumption in the olfactory bulb of the tree shrew, Tupaia glis. Brain Res 124 147-153.

Stewart WB, Kauer JS, Shepherd GM (1979) Functional organization of rat olfactory bulb analyzed by the 2 -deoxyglucose method. J Comp Neurol 185:715-734. 
Thommesen G (1976) Spatial differences in specificity of trout (Salmo trutta L.) olfactory bulb. Acta Physiol Scand 96:6A-7A.

Thommesen $G$ (1978) The spatial distribution of odour induced potentials in the olfactory bulb of char and trout (Salmonidae). Acta Physiol Scand 102:205-217.

Thommessen G, Døving KB (1977) Spatial distribution of the EOG in the rat: a variation with odour quality. Acta Physiol Scand 99:270280
Yamamoto M, Boyer AM, Schwarting GS (1985) Fucose-containing glycolipids are stage- and region-specific antigens in the developing embryonic brain of rodents. Proc Natl Acad Sci USA 82:3045-3049. Ziclinski B, Hara TJ (1988) Morphological and physiological development of olfactory receptor cells in rainbow trout (Salmo gairdneri) embryos. J Comp Neurol 271:300-311. 